\title{
O turismo regional e suas experiências comunitárias no Estado do Acre
}

\author{
The Regional Tourism and its community experience in the Acre State \\ (Brazil)
}

\author{
Dermeson Sousa Lima, Luzia Neide Meneses Teixeira Coriolano
}

\begin{abstract}
RESUMO
No Estado do Acre, o poder público tem firmado parcerias importantes com comunidades tradicionais nas áreas de planejamento, infraestrutura e capacitação visando o desenvolvimento do turismo regional, nos últimos anos. Entre as ações destaca-se a concretização das Rotas Turísticas Regionais em dois pólos, no Vale do Acre e no Vale do Juruá, com cincos roteiros turísticos. Neste contexto, o trabalho aborda as potencialidades dos atrativos das regiões e as experiências do turismo base local em áreas indígenas e extrativistas, dando maior atenção à experiência de turismo comunitário no Projeto de Assentamento Agroextrativista Chico Mendes - PAE CM, com a implantação da Pousada Ecológica Cachoeira administrada pelos assentados. O aprofundamento teórico e os passos metodológicos com o levantamento da realidade na pesquisa de campo no PAE CM, assim como a realização de entrevistas e questionários revelaram as riquezas do assentamento Chico Mendes. Os resultados demonstraram que os roteiros turísticos têm no patrimônio histórico-cultural e ambiental os principais atrativos, adicionados às experiências das populações tradicionais. $O$ arranjo produtivo local desponta como consolidação do turismo regional de base comunitária, que resignifica e reordena o lugar revalorizando as comunidades locais.

PALAVRAS-CHAVE: Roteiros Turísticos; Turismo Comunitário; Projeto de Assentamento Agroextrativista Chico Mendes; Xapuri (AC).
\end{abstract}

\section{ABSTRACT}

In the state of Acre, public power has signed important partnerships with tradicional communities in infrastructure, planning and capacity, aiming the development of regional tourism in recent years. Among these actions it stands out the development of the Regional Tourism Routes in two poles, in Vale do Acre and Vale do Juruá, with five tourist tours. In this context, this study approaches the potential attractiveness of these regions and local tourism base in indigenous and extractive areas, with a main focus on community tourism experience in the Chico Mendes Agroextractivist Settlement (PAE CM), with the introduction of the of the Cachoeira Ecological Inn which is administered by settlers. The theoretical study and methodological basic with the survey of reality based on field research, in the PAE CM as well as interviews and questionnaires revealed the richness from Chico Mendes Settlement. The results showed that tourist tours have historic cultural and environmental heritage the main attraction, added to the experiences of traditional populations. The local productive arrangement appears as a consolidation of a regional community-based tourism, which reframes and reorders the place revaluing local communities.

KEYWORDS: Tourist Tours; Community-Based Tourism; Chico Mendes Agroextractivist Settlement; Xapuri (AC, Brazil). 


\section{Introdução}

A atividade turística no Estado do Acre é recente, reporta-se ainda aos anos noventa, após participação pública e privada no fortalecimento de produtos, implantação de infraestrutura e consolidação de destinos turísticos regionais. Estes aspectos quando aplicados ao turismo no Acre são alicerçados no patrimônio, histórico, cultural e natural, como atrativos na base da formação socioeconômica que possibilita o aproveitamento das peculiaridades regionais, que somadas em conjunto revelam à forte presença da questão ambiental voltada a sustentabilidade que são também adicionados a questão turística.

No contexto atual, parcerias entre governo federal e estadual buscam a efetivação da atividade turística no Estado do Acre, destacando-se algumas ações estatais, parcerias públicas, privadas e comunitárias. Neste âmbito, na década passada foram implantadas políticas do Governo Federal via Ministério do Turismo - MTUR, destacando-se o Programa de Regionalização do Turismo, buscando a consolidação de produtos e implementação de roteiros turísticos regionais em todo o território acreano seguindo o ocorre no país.

No Estado roteiros foram denominados "Rotas Turísticas Regionais do Acre", definidas em dois pólos, o Pólo do Vale do Acre e o Pólo do Vale do Juruá. Sendo o primeiro roteiro composto pelos "Caminhos de Chico Mendes", "Caminhos da Revolução" e "Caminhos do Pacífico" e no Vale do Juruá pela rota "Caminho da Biodiversidade e das Aldeias". Todos estes formando corredores interligados voltados à divulgação de informações de produtos turísticos. Esses roteiros serão discutidos na primeira parte do trabalho, e relatam-se posteriormente experiências de turismo de base local alocados nestes roteiros. Em outro momento, como objetivo principal deste trabalho, relata-se a experiência de turismo de base local no Projeto de Assentamento Agroextrativista Chico Mendes - PAE CM, localizado no município de Xapuri-AC, após a implantação da Pousada Ecológica Cachoeira, administrada pela comunidade adquirindo características do turismo de base local.

Este trabalho teve como pressuposto metodológico uma visão crítica e menos ingênua afastando-se do positivismo. Adota abordagem quanto qualitativa e exploratória. A revisão da literatura realizada inicialmente, somada a coleta de dados "in loco", levantamento de informações e observações em campo, aplicação de questionários e entrevistas realizadas com a ajuda e participação das comunidades que realizam atividades turísticas comporão a metodologia do trabalho. Portanto, o debate aqui aludido sobre turismo comunitário entrelaçou roteiros turísticos regionais com os diversos elementos da valorização comunitária endógena. Coma realidade explicada no contexto da realidade geoambiental, socioeconômica, histórica e cultural. Tendo como foco o Projeto de Assentamento Agroextrativista Chico Mendes e a Pousada Ecológica Cachoeira, que apontam como fortes potencialidades, alternativas de renda para o turismo de base local e para a população extrativista.

\section{O Estado do Acre nas Rotas Turísticas Regionais}


O Governo Federal via Ministério do Turismo - MTUR aplica estratégias para consolidar o turismo como uma atividade indutora do desenvolvimento regional, econômico e de inclusão social para o Brasil com implementação de planos, programas e projetos regionais para consolidar o turismo. Dessa forma, é lançado o Programa Nacional de Turismo em duas edições (2003-2007 e 20072010). Diversos macroprogramas articulados e estruturados pelos princípios da flexibilidade, articulação e mobilização pela política nacional do turismo tentam fortalecer o turismo interno. Esse Plano Nacional destaca o Programa de Regionalização do Turismo - Roteiros do Brasil, considerado marco de descentralização na busca da expansão da oferta turística, induzido pelo setor público, para estruturação de roteiros turísticos regionais em municípios com potenciais turísticos. "Um dos objetivos do programa de regionalização é desconcentrar a oferta turística brasileira, localizada inicialmente de forma predominante no litoral, propiciar a interiorização da atividade e a inclusão de novos destinos nos roteiros comercializados no mercado interno e externo". (BRASIL/PNT, 2007, p.25).

A ação estatal busca a descentralização de políticas em viés mais democrático e participativo, com interação e articulação dos órgãos públicos competentes da área nas esferas federais, estaduais e municipais. A política do MTUR, com planejamento sistematizado, estratégico e participativo na esfera estadual, onde se efetivou por meio de ações, planos e programas agora divulga, potencializa e consolida a atividade em todo o país.

\begin{abstract}
Para a implantação do Programa de Regionalização, realizou-se, em 2004, o primeiro mapeamento do território nacional, que serviu para que se identificassem 219 regiões turísticas que compreendem 3.203 municípios. Considerando que o turismo é um setor dinâmico, a revisão desse mapeamento, em 2006, resultou no 2ำ Mapa de Regionalização do Turismo, abrangendo 200 regiões e 3.819 municípios. Com o amadurecimento do turismo em âmbito estadual, a iniciativa de realizar um novo mapeamento partiu das 27 unidades da Federação. Apresentado na 4⿳亠丷厂 edição do Salão do Turismo, o 3ํㅡㄹ Mapa de Regionalização do Turismo contempla 276 regiões e 3.635 municípios (BRASIL, 2009, p.21).
\end{abstract}

A regionalização propõe o desenvolvimento de ações centradas como indução do turismo regional nas unidades municipais, com inventário da oferta turística realizado pelo MTUR e instituições parceiras em todos os âmbitos e os Destinos Indutores do Desenvolvimento Turístico Regional em conjunto de 65 destinos de turismo nacional, incluindo todas as capitais dos Estados, com investimentos técnicos e financeiros realizados pelo MTUR em parcerias públicas e privados. (BRASIL, 2009).

Neste contexto, no Estado do Acre as políticas públicas voltadas ao turismo foram implantadas em processo contínuo sempre alavancado pelo poder público, o que fez surgir efeitos em longo prazo, entrelaçado em parcerias privadas, e em poucos casos contemplando comunidades. Assim, as ações foram determinantes para a atividade turística e muitos veem nelas alternativas de desenvolvimento regional e local. Tais iniciativas possibilitam a elaboração e 
implementação de rotas turísticas regionais nos territórios que agregam elementos primordiais para o desenvolvimento turístico como: infraestrutura preliminar, ou seja, vias de acesso, energia e comunicação, além de produtos e aspectos comercializados como roteiros turísticos regionais.

E assim, no Acre, o turismo é viabilizado por política pública voltada ao desenvolvimento e consolidação da atividade turística, implementada por gestores públicos. Os estudos preliminares foram executados ainda na década passada em parceria com Serviço de Apoio às Pequenas Empresas do Acre SEBRAE/AC, a Secretaria de Estado de Turismo - SETUR ${ }^{1}$, articulados MTUR e outras entidades da área numa parceria pública, privada e comunitária.

Destaca-se o Zoneamento Econômico Ecológico - ZEE/AC, Fase I (2000) e Fase II (2006) que subsidia o desenvolvimento turístico no Estado do Acre fornecendo condições necessárias para projetos voltados ao desenvolvimento do Acre. A proposta ressalta o potencial das regiões do Acre para o turismo, sendo resultado à divisão territorial do Estado em dois pólos turísticos (Pólo Turístico do Vale do Acre e Pólo Turístico do Vale do Juruá), possibilitando a efetivação de políticas públicas que visam à consolidação de infraestrutura turística nas duas mesorregiões.

\section{Os pólos turísticos potencializam experiências comunitárias}

A atuação estatal no setor turístico no Estado do Acre foi de grande importância para desenvolvimento turístico regional, pois a efetivação de políticas públicas, planejamentos e estudos potencializaram os territórios regionais e locais. Assim, os pólos turísticos do Vale do Juruá e do Vale do Acre vivenciam experiências de turismo com participação de comunidades e crescem de forma nítida. O Pólo do Vale do Juruá é justificado pela exuberância do patrimônio natural protegido, comunidades indígenas e extrativistas, enquanto o pólo do Vale do Acre por dispor de infraestrutura de acesso, metas de integração com os países fronteiriços, com produtos turísticos consolidados em estágio de desenvolvimento, valorizando o patrimônio ambiental, histórico e cultural tornamse pontos fortes para o desenvolvimento da atividade turística regional.

Estudos foram efetivados nos dois polos no Estado, nas mesorregiões: Vale do Acre e Vale do Juruá, e confirmam e potencialização da oferta de serviços, produtos, infraestrutura de acesso e atrativos qualificados. Há esforço para possibilitar melhor planejamento e aplicação de recursos e nas ações turísticas. Os pólos do Estado do Acre podem ser observados na Figura 1 (próxima página) ${ }^{2}$.

A implantação do Programa de Regionalização do Turismo definindo Rotas Turísticas do Acre e cinco roteiros que valorizam as potencialidades regionais dos municípios transformando-os em produtos turísticos já estabelecidos e com melhor infraestrutura. A mesorregião do Vale do Acre, melhor servida de serviços de apoio a atividade turística, sendo a capital, Rio Branco, encontra-se em processo de urbanização em estágio consolidado caracterizando-se como portão de entrada de turistas no Estado. Além se der o pólo dispersor de turistas para os roteiros. Já o Pólo do Vale do Juruá fica em desvantagem por ter infraestrutura de acesso deficiente tornando os custos de passagens mais dispendiosos. 


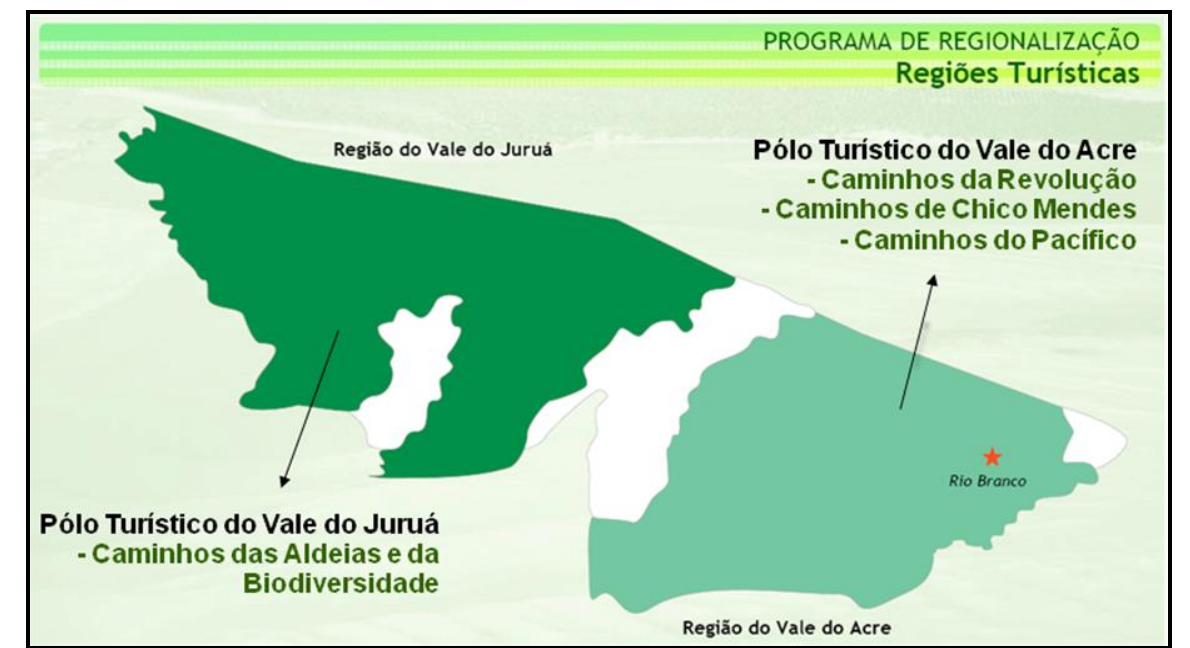

Figura 1: mapa dos pólos turísticos do Estado do Acre. Fonte: SETUL (2009). Figure 1: Map of the State of Acre tourism centers. Source: SETUL (2009).

Apesar das deficiências com relação à infraestrutura, o Juruá possui ricas potencialidades por suas belezas cênicas e etnocultural, que são os principais atrativos da rota "Caminho das Aldeias e da Biodiversidade". Engloba todos os municípios da Regional do Juruá, destacando-se o Parque Nacional da Serra do Divisor - PNSD e as várias comunidades extrativistas e indígenas distribuídas em terras indígenas e projetos de assentamento. A rota regional engloba ainda os municípios da Regional Tarauacá/Envira com forte apelo ao turismo etnoturismo ligado à cultura dos povos indígenas e turismo de base comunitária ligados a comunidades extrativistas. Os principais produtos da rota concentram-se na área urbana do município de Cruzeiro do Sul ponto de partida da rota, composta pelo Roteiro do Juruá e Roteiro Balneários, sendo o primeiro ligado ao turismo cultural: visitas de igrejas, museus, mercados e teatros da cidade e o segundo roteiro ligado aos balneários, igarapés e rios que banham a região.

Destaca-se também na regional os eventos culturais, religiosos, sobressaindo os festivais de praias realizados em vários municípios, a Expojuruá, em Cruzeiro do Sul, ligada ao turismo de eventos e negócios, Festival do Açaí em Feijó, Festival do Abacaxi em Tarauacá, festas estas ligadas aos valores culturais e econômicos, festividades ligadas ao turismo religioso como o novenário de Nossa Senhora da Glória, em Cruzeiro do Sul e em Tarauacá as comemorações ao padroeiro do município, na Festa de São Francisco.

A mesorregião do Vale do Juruá possui diversos atrativos com grande potencial para o desenvolvimento do turismo de base local, e prepara-se para a oferta do turismo comunitário. O patrimônio ambiental, e o cultural material e imaterial da população da região ajudando consolidar o turismo na Amazônia e no Estado do Acre. Essa região concentra a maior parte da extensão territorial indígena possuindo 29 terras indígenas do total de 36 terras reconhecidas pela Fundação Nacional do Índio - FUNAI no Estado. Além de áreas extrativistas e florestais configuradas em projetos de assentamentos agroextrativistas - PAE e Reservas Extrativistas - RESEX, destacando a RESEX Alto Juruá, Riozinho da Liberdade e Alto Tarauacá e as Florestas Estaduais - FLOE, do rio Liberdade, do Mogno e do Rio Gregório, ocupando na região um território que corresponde a 8,82\% do Estado. Destaca-se também o Parque Nacional da Serra do Divisor PNSD, o ponto mais ocidental do Brasil, que ocupa 4,77 \% da extensão territorial 
do Estado, território de grande interesse ecológico, científico e recreacional, repleto de trilhas, cachoeiras, cursos d'água e serras, diversidade de espécies da fauna e flora amazônica até então pouco estudada, além de outros atrativos. (ACRE, 2008).

As unidades de conservação no Vale Juruá despontam pelo seu rico patrimônio ambiental e cultural para atividades ligadas ao turismo comunitário e ecoturismo. Assim, nos últimos anos a organização comunitária, possibilitou a formação de cooperativas e associação de moradores representando a população indígena de algumas aldeias que tem se organizado em torno de festivais de culturas indígenas, divulgando suas culturas, rituais e tradições, que somados ao patrimônio ambiental tem movimentado a atividade turística de forma organizada, divulgando e comercializando pacotes turísticos, sendo todos estes um produto diferencial no mercado turístico por possibilitar a vivencia com essas populações. "O turismo étnico ou etnoturismo é alimentado pelo interesse dos visitantes em ter acesso à cultura e ao povo indígena, buscando conhecer seus costumes e crenças no próprio ambiente de vivência dos mesmos" (LEAL, 2009, p.246).

Em relação ao turismo etnocultural, ligado a questão indígena destaca-se o Festival Indígena Yawanawá e Xinã Benã, no município de Tarauacá e Jordão que reúnem várias aldeias da região, nas comemorações e rituais que fazem o uso tradicional do chá da Ayahuasca e da caiçuma (bebida tradicional fermentada da mandioca), kampô (vacina do veneno de anfíbios) e o rapé (inalador de casca de árvores, ervas e tabaco), Entre outras danças e rituais tem despertado curiosidade vários visitantes e o aumento do fluxo de turistas nos últimos anos. As organizações indígenas comunitárias também estão presentes e algumas comunidades indígenas próximas à cidade de Cruzeiro do Sul, Mâncio Lima, Marechal Thaumaturgo e Porto Walter realizando atividades etnoculturais aproveitadas pelo turismo de base local.

As comunidades têm apoio e fazem parcerias com órgãos públicos ligados à área e ao turismo, além de contarem com o apoio de organizações não governamentais e assim, realizam ações para a consolidação e a divulgação de suas culturas, realizam atividades ligadas ao artesanato, etnoturismo, materiais didáticos e audiovisuais, e principalmente focados ao turismo comunitário. Dominando toda a logística de transporte, hospedagem e entretenimento, sendo os pacotes turísticos comercializados pelas próprias associações indígenas. Estes aspectos retratam a adequação das comunidades tradicionais as alternativas de renda com pluriatividades, destacando-se as ligadas ao turismo de base comunitária.

Sobre o envolvimento dos povos indígenas com o turismo, também é necessário relativizar, uma vez que é preciso inicialmente desenvolver uma reflexão sobre como tais povos têm extraído condições de garantir sua existência nesse cenário capitalista desigual, utilizando-se também da atividade turística como possibilidade de revitalização cultural. Os estudos antropológicos atuais consideram as aldeias indígenas não só como receptoras passivas do fluxo de visitantes, mas também como empreendedoras turísticas atuantes, que dialogam com a estrutura oficial do setor. (LEAL, 2009, p. 243). 
A região do Vale do Juruá apresenta desvantagem, em relação às demais, por questões de logística relacionada à infraestrutura de acesso. Contudo a região passa por processo de integração rodoviária com a pavimentação da BR-364 que ligará a capital Rio Branco ao extremo com a segunda maior cidade que é a de Cruzeiro do Sul, sendo o deslocamento aéreo para esta região requer altos custos, enquanto o transporte terrestre e fluvial que é influenciado pelas condições climáticas e geomorfológicas dos rios e do solo da região que dificulta e onera o acesso à região por ser necessário romper longas distâncias. Estas dificuldades estão sendo melhoradas com a pavimentação em grande parte da rodovia federal BR-364, ligando a cidade de Rio Branco à Cruzeiro do Sul nos últimos anos que tem possibilitado o tráfego terrestre permanente para região.

Já a mesorregião do Vale do Acre, com patrimônio histórico-cultural e ambiental rico desponta para o turismo de base comunitária, no qual, nos anos 1980 e 1990 o movimento ambientalista e os conflitos agrários pela posse de terra o que fez configurar diversos projetos de assentamentos e unidades de conservação de uso sustentável que foram adequados a territorialidade extrativista. Destacam-se neste contexto, os projetos agroextrativistas Chico Mendes, Santa Quitéria, Remanso e Equador por suas organizações comunitárias e atividades socioeconômicas (extrativismo vegetal e agricultura familiar) e condições de acesso facilitam a exploração do turismo de base comunitária (LIMA; CORIOLANO, 2010).

No que se refere a territórios de uso sustentável com potencial para o desenvolvimento turístico, destaca-se a Reserva Extrativista Chico Mendes, considerada marco de regularização fundiária oriunda movimentos sociais e demandada pelas populações tradicionais da Amazônia e do Acre, preservando a territorialidade seringueira, seu rico patrimônio histórico-cultural e ambiental. Sendo esta unidade de conservação de uso sustentável a maior do Brasil e do Acre, abrange territorialmente sete municípios em uma área de 970.570,00 ha, o que corresponde a 5,66\% de sua extensão territorial (ACRE, 2008).

Estes aspectos estão inseridos e valorizados no pólo turístico do Vale do Acre, nas rotas turísticas regionais que se encontram em estágio mais avançado desenvolvimento podendo ser considerado processo de consolidação, por ter a melhor infraestrutura acesso, já tendo vários roteiros/produtos comercializados. Todos os serviços de agenciamento e transporte de serviços turísticos tem a cidade de Rio Branco como polo irradiação, considerada a porta de entrada do Estado, contanto ainda com a melhor infraestrutura de hospedagem, alimentação e entretenimento turístico. Ainda nesse pólo foram implantados três roteiros turísticos, que fazem parte do projeto "Roteiros do Brasil", em estágio já estabilizado sendo divulgados nacionalmente e no exterior, comercializados pelas agências de turismo locais.

O Pólo do Vale do Acre encontra-se em estágio mais avançado de implantação. Nele foram definidas três rotas, denominadas caminhos (Caminhos Chico Mendes, do Pacífico e da Revolução), que receberam investimentos em atrações, hotelaria, infraestrutura de acesso e, em breve, sinalização adequada. Merece destaque, ainda, a formação de pessoal para o setor, tanto no nível superior, com os cursos de graduação criados pelas faculdades privadas, quanto no nível técnico, através de centros de formação do governo, com os cursos de guia de turismo regional e técnico em ecoturismo (ACRE/PPA, 2008, p.35). 
Entre os roteiros destaca-se a Rota Caminhos da Revolução que engloba os municípios de Rio Branco, Plácido de Castro e Porto Acre e tem como ponto forte a pousada do Seringal Bom Destino, localizada em Porto Acre, voltados aos aspectos históricos culturais do Estado; a Rota Caminhos de Chico Mendes que tem como principal atrativo as questões ambientais e culturais tendo como ponto forte história de vida do líder seringueiro Chico Mendes. Envolve os municípios de Rio Branco, Xapuri, Senador Guiomard e Capixaba, sendo Xapuri, o local onde nasceu e viveu o líder seringueiro, o destino principal da rota, com destaque à Pousada Ecológica do Seringal Cachoeira no Projeto de Assentamento Agroextrativista Chico Mendes - PAE CM. A rota denominada Rota Turística Caminhos do Pacífico abre possibilidades de integração aos países vizinhos Bolívia e Peru pela Rodovia Interoceânica, ou, como é conhecida no Brasil, Estrada do Pacífico. Conta com infraestrutura de hospedagem e alimentação nos municípios que fazem parte do circuito, destacando-se em Brasiléia a Pousada Vila Brasília e em Assis Brasil e a Pousada Jaraguá. Este roteiro envolve os municípios de Rio Branco, Senador Guiomard, Capixaba, Plácido de Castro, Xapuri, Brasiléia, Epitaciolândia e Assis Brasil, todo esse roteiro conta com sinalização turística, infraestrutura de acesso, hospedagem e alimentação.

Assim, com intuito de criar e consolidar as rotas turísticas para a região do Vale do Acre, o poder público estadual e federal contrai financiamentos e busca convênios, além de parceria com iniciativa privada para consolidar as Rotas Turísticas Regionais, buscando efetivar a atividade como alternativa econômica e social sustentável para o Estado do Acre. Em todas as rotas foram criadas infraestrutura de hospedagem, entre estas se destaca a Pousada Cachoeira no PAE CM, que desenvolve experiência da comunidade extrativista com o turismo comunitário. Assim, a ação estatal propicia condições favoráveis à geração de atrativos e infraestrutura, objetivando a expansão da oferta turística regional e a integração aos países vizinhos da Bolívia e Peru, um mercado promissor.

\section{O turismo comunitário no PAE CM e a experiência na Pousada Ecológica Cachoeira}

No Acre, a organização social e política das populações tradicionais foram de fundamental importância para se criar uma estrutura fundiária específica adaptada às peculiaridades regionais no final do século $\mathrm{XX}$ : o respeito à configuração dos seringais nativos e a cultura da população residente. Assim, nova estrutura fundiária foi criada a partir da demanda dos movimentos socioambientais e foram retratadas na criação das reservas extrativistas e nos projetos de assentamentos agroextrativistas. Com o passar dos tempos as populações tradicionais passam a desvalorizar o extrativismo vegetal devido os problemas a pouca valorização da produção no mercado e buscam alternativas de renda no turismo com vista ao desenvolvimento local.

Neste contexto, a população desenvolve práticas de hospedagens desde tempos remotos, reportando-se ao período da colonização do território acriano, estendendo-se à época dos conflitos socioambientais pela posse de terra nos anos 70/80, caracterizando acolhimento de seus parceiros de luta uma hospedagem do tipo familiar, fazendo da hospitalidade elemento marcante na identidade xapuriense e acreana. Nos anos de 1990, através de organização social (associação de moradores) adota em sistema de mutirão, material e mão 
de obra, as condições para construção na sede do PAE CM, a Fazendinha, a primeira pousada para receber visitantes, realizar eventos e acolher seus parceiros de luta em defesa de seus territórios (Figura 2).

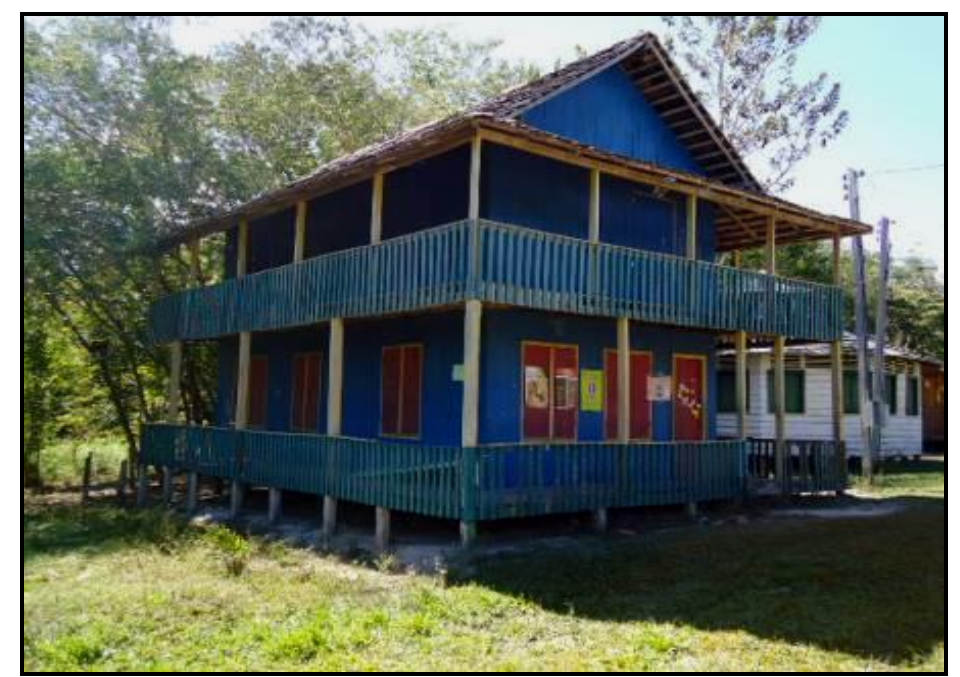

Figura 2: A primeira pousada implantada pela comunidade no PAE CM. Fonte: Arquivo Dermeson Lima (2009).

Figure 2: The first hostel located by the community in PAE CM.

Source: Dermeson Lima Archive (2009).

A comunidade presta serviços de recepção, guias, hospedagem e transporte para visitantes, grupos de pesquisadores, estudantes e turistas que vão conhecer o lugar onde viveu o ambientalista Chico Mendes, e o local que eclodiram os conflitos pela preservação da floresta. A primeira pousada preserva arquitetura original servindo como espaço alternativo para comunidade, onde se realizam as reuniões, estudos e capacitações.

A Comunidade Fazendinha concentra oferta e serviços de turismo, sendo também ponto estratégico do assentamento para os moradores que possui infraestrutura e oferece serviços de saúde, educação, transporte e sede da associação de moradores, atendendo a população do PAE CM. No local ainda residem descendentes da família de Chico Mendes que exercem liderança comunitária, que prestam serviços de guias e contadores de histórias retratando toda história de luta em defesa do meio ambiente daquela localidade. Em determinados momentos o fluxo de visitantes na localidade é maior que a de residentes na Comunidade Fazendinha.

A infraestrutura de hospedagem da Pousada Cachoeira possui capacidade de 31 leitos, distribuídos em 03 chalés e dois quartos coletivos, sendo dois chalés para casal e um para família com a capacidade para 04 hóspedes, enquanto 02 belichários (quarto com conjunto de camas sobrepostas) têm capacidade para 24 hóspedes, todos podendo comportar, além do citado, camas extras e chegar a um total geral de 45 leitos. A infraestrutura conta com recepção, cozinha, bar, restaurante, parque infantil, lago/açude, três piers para pescaria, trilhas ao redor da pousada, uma casa demonstrativa de defumação de borracha, piscina e estacionamento de veículos. A pousada oferece também atividades de arborismo, ciclismo, 
pescaria, arvorismo e tirolesa ${ }^{3}$ com instrutores e infraestrutura adequada respeitando as normas de segurança.

$\mathrm{Na}$ pousada os serviços internos são desempenhados pelos comunitários que são contratados como trabalhadores fixos e temporários, ou seja, a pousada absorve a mão de obra local da comunidade. Sendo os mesmos capacitados em diversos cursos de turismo, gastronomia e hotelaria. Os trabalhadores fixos são formados por 03 camareiras, 03 cozinheiras, 02 vigias, 01 funcionário, que realiza serviços gerais, e 01 gerente responsável pela administração da pousada formado em turismo e hotelaria. A ocupação dos trabalhadores ligados à pousada que oferece serviços ao turismo é visualizado na Figura 3:

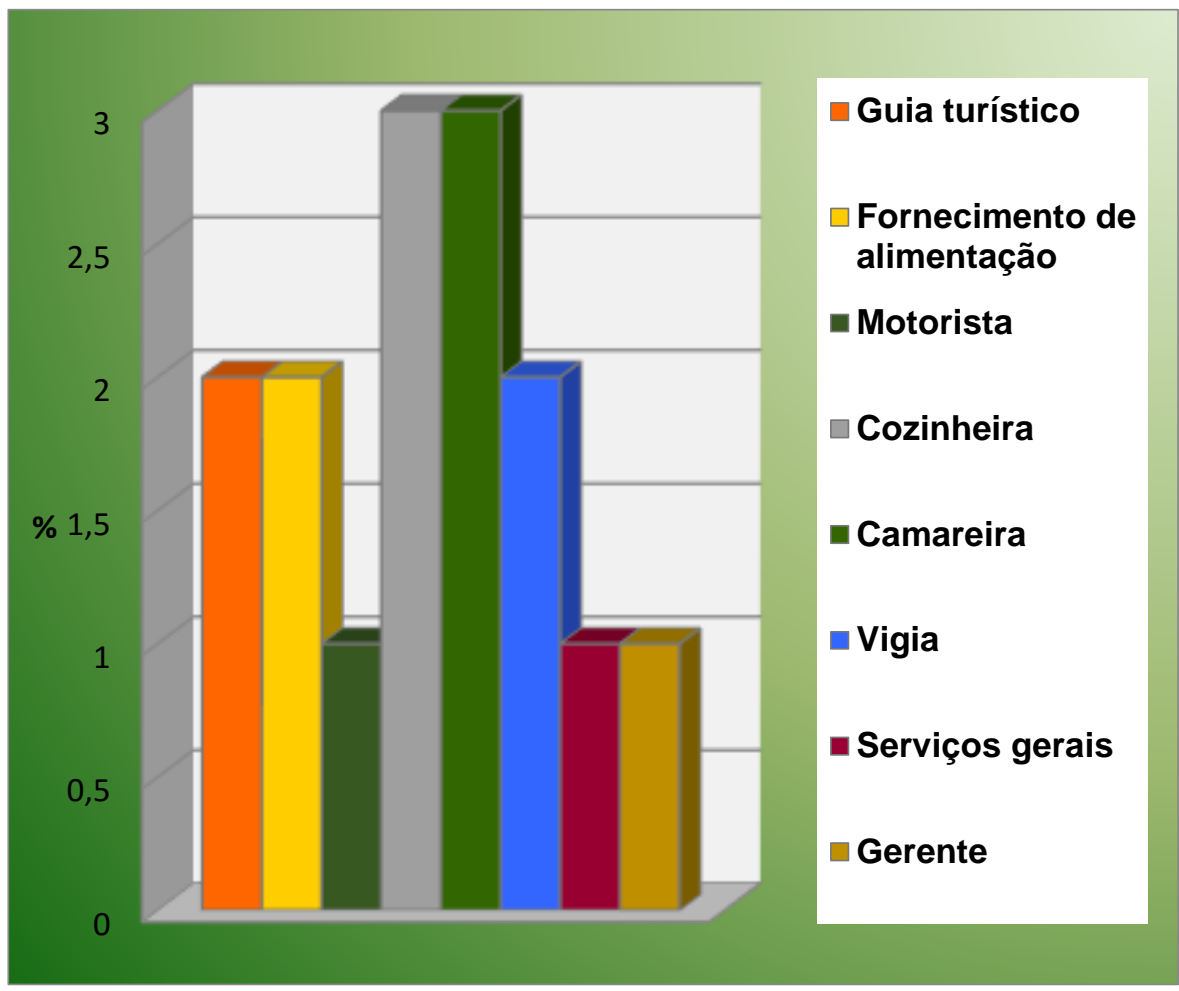

Figura 3: População envolvida diretamente com o turismo comunitário. Fonte: Pesquisa de campo (2010). Figure 3: Population directly involved with community tourism. Source: Field Research (2010).

Os trabalhadores eventuais são representados por 02 guias turísticos, 02 fornecedores de alimentação para pousada (frutas, animais domésticos e produtos agrícolas), 03 três assentados que participam de atividades de entretenimento, como contadores de histórias e bandas músicas regionais, ou de "forrozeiros". Ressalta-se que este grupo está sujeito a sazonalidades, ampliando-se conforme a necessidade e o fluxo da demanda de turistas e de eventos na pousada. Segundo levantamento realizado pelo CTA (2008), a população total do PAE CM corresponde a 391 pessoas, enquanto a população envolvida diretamente com atividade turística gira em torno de $05 \%$, percentual justificado devido às atividades atreladas ao turismo se concentrarem na sede do PAE CM ${ }^{4}$.

Os trabalhadores de maneira geral envolvidos com o turismo, em média 50 pessoas, quando questionados se prestaram ou venderam produtos alimentícios para pousada no último ano, 76,47\% responderam que comercializam algum tipo de produto, entre os quais se destacam polpas e frutas regionais, animais 
domésticos, produções agrícolas, especificamente derivados da mandioca como farinha, tucupi e goma de tapioca, além de artesanatos de sementes, doces e castanhas. As práticas demonstram o encadeamento do turismo com as demais atividades socioeconômicas do assentamento, principalmente a agricultura familiar e extrativismo vegetal, por participarem no suprimento alimentar da pousada.

A análise do cenário possibilita diversas interpretações. Cabe ressaltar que os trabalhadores envolvidos com a atividade do turismo, podendo-se depreender, que $100 \%$ dos entrevistados têm algum tipo de ligação com a atividade de forma direta ou indireta (cerca de $05 \%$ da população total). Neste universo do turismo, $64,7 \%$ dos entrevistados prestam serviços permanentes à pousada, o tempo de dedicação a outras atividades econômicas torna-se inviável ou insuficiente, ficando a cargo dos demais membros das famílias exploração dessas atividades ou nas horas de folga ou períodos de entre safra.

Nas atividades econômicas desenvolvidas no PAE CM, está presente o manejo florestal madeireiro, a pecuária, que por lucros obtidos, configuram-se como reserva de valor monetário aos assentados, 0 que faz ter representatividade. Sendo que no universo total dos assentados, o manejo florestal comunitário, envolve apenas 19 assentados, retratando a concentração de renda proveniente das mesmas. Vale ressaltar que o desenvolvimento das atividades é impactante ao meio ambiente, apresenta ameaças aos ecossistemas naturais, com impactos na fauna e flora regional e principalmente no turismo uma vez que os visitantes são fortemente atraídos pela contemplação da vida silvestre e da fauna regional.

A principal demanda de turismo para a Pousada Ecológica Cachoeira (Figura 4) é de visitantes regionais que buscam conhecer a experiência de desenvolvimento comunitário em consonância com o meio ambiente. Existe também uma demanda proveniente da realização de eventos de médio e pequeno porte organizados por instituições governamentais e Ong's.

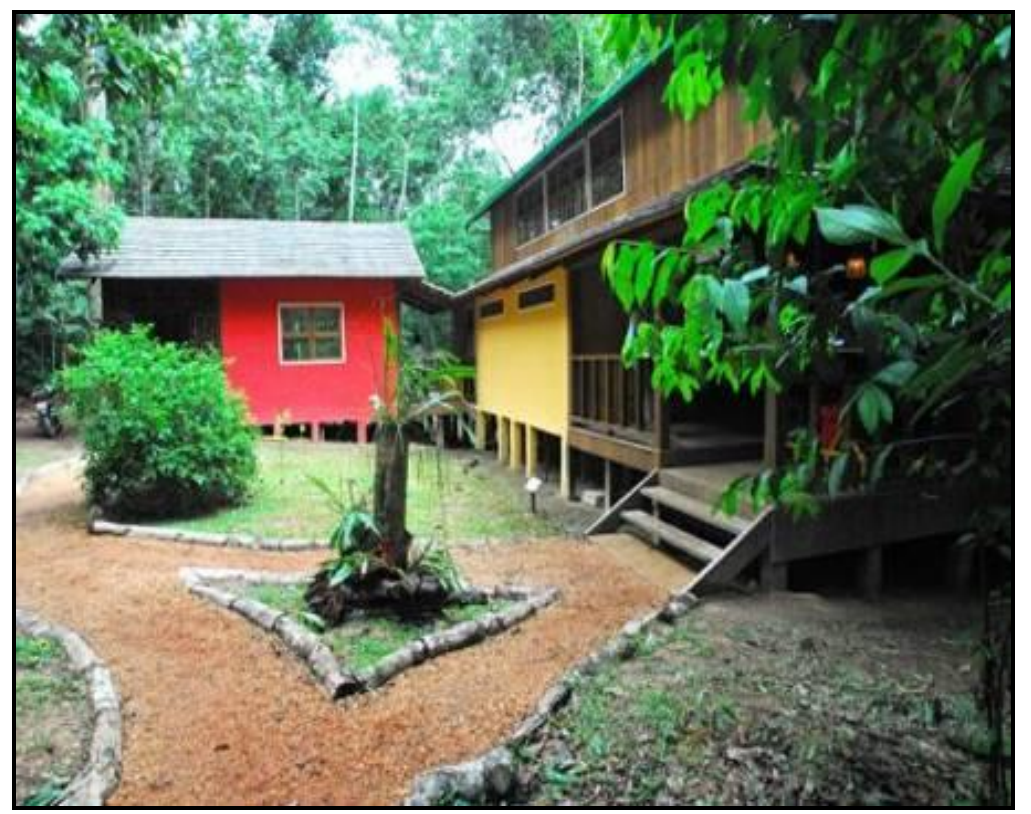

Figura 4: Pousada Ecológica do Seringal Cachoeira. Fonte: SETUL (2010).

Figure 4: Pousada Ecológica do Seringal Cachoeira. Source: SETUL (2010). 
O PAE CM, por se localizar na região de fronteira recebe significante demanda de turistas estrangeiros que estão em trânsito pelos municípios de Brasiléia, Xapuri e Rio Branco e busca outro tipo de turismo mais voltado a questão ecológica, histórica e regional. A Tabela 1 mostra essa demanda, com maiores detalhes dos visitantes da pousada.

Tabela 1: Demanda turística da Pousada Cachoeira 2007-2009.

Table 1: Tourist Demand of the Pousada Cachoeira 2007-2009.

\begin{tabular}{|c|c|c|c|}
\hline Demanda Nacional & $\%$ & Demanda Internacional & $\%$ \\
\hline ACRE & 60,6 & \multirow{3}{*}{ ALEMANHA } & \multirow{3}{*}{8,0} \\
\hline SÃO PAULO & 14,3 & & \\
\hline MATO GROSSO & 4,7 & & \\
\hline PARÁ & 2,5 & \multirow{3}{*}{ ESTADOS UNIDOS } & \multirow{3}{*}{1,0} \\
\hline MINAS GERAIS & 2,0 & & \\
\hline RONDÔNIA & 1,8 & & \\
\hline DISTRITO FEDERAL & 1,7 & \multirow{3}{*}{ PERU } & \multirow{3}{*}{0,2} \\
\hline RIO DE JANEIRO & 1,3 & & \\
\hline PERNAMBUCO & 1,0 & & \\
\hline RIO GRANDE DO SUL & 0,3 & \multirow{3}{*}{ FRANÇA } & \multirow{3}{*}{0,2} \\
\hline MARANHÃO & 0,2 & & \\
\hline AMAZONAS & 0,2 & & \\
\hline TOTAL & 90,6 & TOTAL & 9,4 \\
\hline
\end{tabular}

Fonte: SETUL/Boletim de ocupação hoteleira - Pousada Ecológica Cachoeira, 2010.

Source: SETUL/ Bulletin of hotel occupancy - Pousada Ecológica Cachoeira, 2010.

Segundo dados da SETUL (2010), nos últimos anos, desde a inauguração da pousada no ano de 2007, a mesma recebeu mais de 2.500 visitantes até no final do ano de 2009. A principal demanda turística nesse período é nacional, representada por mais de $90 \%$ de visitantes brasileiros, entre os quais, $60,6 \%$ são acreanos oriundos de Rio Branco, que buscam descanso, lazer e atividades voltadas ao turismo regional. A demanda proveniente do Estado de São Paulo é $14,3 \%$, isto é, visitantes principalmente voltados a turismo de lazer, eventos e negócios. Já para demanda internacional, destacam-se os alemães, que representa a maior parte da demanda internacional interessados em conhecer a história e cultural local. Ao se efetivar no território o turismo utiliza o patrimônio histórico, cultural e ambiental transformando-os em atrativos, o que desencadeia uma série de efeitos no espaço e na economia local. Um modelo de turismo com princípios de sustentabilidade deve buscar valorização dos elementos locais do território e fortalece a base comunitária.

A sazonalidade de turismo no PAE CM é fato, sendo a maior visitação nos meses de janeiro a março, no segundo semestre do ano, período que compreende os meses de julho a setembro, além de depender também dos eventos realizados no local pelos órgãos públicos e instituições privadas, que usam a infraestrutura para realizarem reuniões, capacitações e encontro de negócios e na área ambiental, movimentando a cadeia do turismo no assentamento.

Assim, a instalação da pousada e do desenvolvimento do turismo no PAE CM, oferece roteiros que integram a história e a cultura local, possibilitando contato com os moradores, caminhadas orientadas, participação de festas e eventos que permitem a interação dos visitantes com a 
comunidade absorvendo a mão de obra local em serviços locais de guias, transporte e de entretenimento.

A implantação do turismo no PAE CM, vem possibilitando a melhoria da infraestrutura de acesso ao assentamento, além da compra produtos agrícolas para alimentação dos hóspedes da pousada, venda de artesanatos, e serviços de manutenção da infraestrutura da pousada. Mas por outro lado gera impactos ambientais e culturais, e se não controlados adequadamente, sobrecarga as trilhas, contaminação de recursos hídricos e segregação cultural. Pode o turismo comunitário quando bem planejado envolvendo a população residente de maneira geral, desempenha importante papel na valorização da história, cultura e do lugar fortalece a organização social da comunidade, assim como, o meio ambiente por ter nele um dos principais atrativos. Estes princípios, quando planejados de forma eficiente, propiciam oportunidades de valorizar o potencial endógeno de áreas extrativistas.

\section{Considerações finais}

A implantação dos roteiros turísticos regionais realizados pelo Governo Federal em parcerias locais no Estado do Acre possibilita a valorização do potencial endógeno étnicos de territórios para desenvolvimento turístico de base local e comunitário, em áreas extrativistas e indígenas. Por uma questão de logística, organização social e infraestrutura algumas comunidades agroextrativistas tem se destacado, servindo de exemplo a ser adequado e seguido a comunidades que buscam o desenvolvimento local, como é vivenciado no PAE CM.

O PAE CM com as belezas e cenários paisagísticos, somados aos atrativos históricos, culturais e a organização social da população extrativista, desapontam estes, como atrativo sendo o principal destino do turismo comunitário no Estado do Acre. No que diz respeito à infraestrutura, a construção da Pousada Ecológica Cachoeira e desenvolvimento do turismo de base local constituiu a iniciativa da comunidade junto ao poder público, retratando a importância da parceria pública, privada e comunitária. Desde a implantação e desenvolvimento o turismo no PAE $\mathrm{CM}$, o sentimento comunitário, envolve a população local em todos os estágios e fases de planejamento.

Assim, o turismo se efetiva em parceria com o poder público, e parceria comunitária, em escala territorial configura-se na Comunidade Fazendinha, concentrando os impactos positivos como: oportunidades de geração de emprego e renda, na localidade, e com benefícios indiretos as demais comunidades, pela compra da produção agrícola e artesanato. Para uma localidade ser turística, não basta possuir atrativos, necessita de elementos que outorga as condições básicas das não básicas, necessitando oferecer os serviços de saúde, educação, acesso para possibilitar qualidade de vida aos demais residentes como foi retratado no caso desta comunidade. Faz-se necessário o apoio irrestrito do Estado, para oferecer atividades não-básicas tanto aos visitantes e residentes.

Desta forma, o turismo no PAE CM, envolve o trabalho da comunidade em todas as fases, principalmente no planejamento e na prestação de serviços ao turista, devendo incentivar a organização da hospedagem familiar nas demais comunidades, capacitações profissionais, agregação de valor aos produtos, serviços e na agricultura familiar, diversificação de roteiros turísticos, 
manifestações culturais, gastronomia regional e artesanato. $E$, sobretudo revaloriza o patrimônio histórico-cultural e geoambiental das populações tradicionais ao inserir saberes e tradições nos roteiros e produtos valorizados pelo turismo, além de oportunizar o aproveitamento da mão-de-obra local, busca de oportunidades de rendimentos suficientes para melhor qualidade de vida. Ressalta-se a importância da vontade política e a efetivação de parcerias e sinergias para concretização do turismo de base local, princípios estes, que podem ser aplicados no PAE CM.

Portanto conclui Coriolano (2006) que a produção de territórios solidários e de práticas de turismo solidário não é um fim em si mesmo, são práticas políticas para além do turismo, o que as comunidades desejam, em última instância é uma sociedade justa, oportunidades e direitos iguais para todos. Ao lado do turismo global caminha a passos largos o turismo de base comunitária, que apresenta especificidade de ser solidário, com indícios de outro turismo. Contudo as contradições da sociedade de consumo se reproduzem nas comunidades, visto que o capitalismo se dá em cadeia e em várias escalas. Embora as comunidades lutem pela solidariedade e cooperação entre membros, muitas vezes, o realce à solidariedade, coesão e existência de interesses comuns, desconhecendo a realidade, tende a conduzir a ação social à promoção e reprodução da ordem social.

\section{Referências bibliográficas}

ACRE. Governo do Estado. Fundação de Cultura e Comunicação Elias Mansour FEM. Povos indígenas no Acre. Rio Branco - AC: FEM, 2010.

ACRE.Fundação de Tecnologia do Estado do Acre - FUNTAC. Atlas do Estado do Acre. Rio Branco-AC: FUNTAC, 2008.

ACRE. Secretaria de Estado de Esporte Turismo e Lazer - SETUL. Boletim de ocupação hoteleira da Pousada Ecológica Seringal Cachoeira. Rio Branco - AC: SETUL, 2010.

ACRE. Secretaria de Planejamento - SEPLAN. Plano Plurianual (PPA 20082011). Rio Branco-AC: SEPLAN, 2008. Disponível em: <http://www.ac.gov.br/> Acesso em: 30 de março de 2010.

ACRE. Secretaria de Turismo - SETUR. Estratégias do Governo do Estado do Acre para o desenvolvimento do Turismo. Rio Branco - AC: SETUL, 2009. (Palestra apresentada na XIX Semana Chico Mendes, realizada na Biblioteca da Floresta "Marina Silva").

BRASIL. Ministério do Turismo - MTUR. Plano Nacional de Turismo 2007-2010. Brasília: MTUR, 2007. Disponível em: $<$ http://www.turismo.gov.br/turismo/o ministerio/plano nacional/>. Acesso em: 10/02/2009.

BRASIL. Estudo de Competitividade dos 65 destinos Indutores do Desenvolvimento Turístico Regional - Relatório Brasil. $2^{2}$ ed. Brasília-DF: MTUR, 2009.

CORIOLANO, L.N.M.T. O turismo nos discursos, nas políticas e no combate à pobreza. São Paulo: Annablume, 2006. 
LEAL, R.E.S. O turismo desenvolvido em territórios indígenas sob o ponto de vista antropológico. In: BARTHOLO, Roberto; SANSOLO, Davis G.; BURSZTYN, Ivan. (Org.). Turismo de Base Comunitária diversidade de olhares e experiências brasileiras. Rio de Janeiro - RJ: Letra e Imagem, 2009. p. 240-248.

LIMA, D.S.; CORIOLANO, L.N.T. Na fronteira do turismo: as perspectivas de desenvolvimento regional na microrregião do Alto Acre. In: XVI Encontro Nacional de Geógrafos. 2010, Porto Alegre - RS. Anais do XVI ENG. Porto Alegre - RS: AGB Nacional, 2010, p. 01-12. Disponível em: <http://www.agb.org.br/evento/download.php =3921 >. Acesso em: 10 jul. 2012.

\section{Notas}

${ }^{1}$ O órgão público responsável pela execução do turismo no Estado era a Secretaria de Estado de Turismo - SETUR, passando em momentos posteriores, em outras gestões políticas administrativas, a área fazer parte da Secretaria de Estado de Esporte, Lazer e Turismo - SETUL.

${ }^{2}$ Nos estudos do ZEE (2006) e da SETL (2006) foram supridos os municípios de Acrelândia, Manuel Urbano, Santa Rosa do Purus na Mesorregião do Vale do Acre, e os municípios de Jordão na Mesorregião do Vale do Juruá por falta de atrativos suficientes e infraestrutura para se tornarem produtos.

${ }^{3}$ Referem-se a atividades esportivas, recreativas e de lazer ligadas ao turismo aventura e ao ecoturismo que consiste na pratica de locomoção e travessias em cordas, cabos de aço ou em plataformas suspensas em copas das árvores de grande porte para observação da fauna e flora.

${ }^{4}$ Ressalta-se que atividade turística concentra-se na sede do PAE CM, na Comunidade Fazendinha e envolve diretamente a população residente no seu entorno, acrescidos da questão de logística, pois a comunidade é o principal acesso ao projeto de assentamento tendo tráfego regular. Enquanto as demais comunidades não contam com produtos turísticos consolidados e boas condições de acesso

Dermeson Sousa Lima: Universidade de Brasília, Brasília, DF, Brasil.

E-mail: dermeson@zipmail.com.br

Link para o currículo Lattes: http://lattes.cnpq.br/7561316684293306

Luzia Neide Menezes Teixeira Coriolano: Universidade Estadual do Ceará, Fortaleza, CE, Brasil.

E-mail: Iuzianeidecoriolano@gmail.com

Link para o currículo Lattes: http://lattes.cnpq.br/4477795642535596

Data de submissão: 31 de maio de 2012

Data de recebimento de correções: 11 de maio de 2012

Data do aceite: 04 de maio de 2016

Avaliado anonimamente 